\title{
KEBERADAAN PELABUHAN TAPAKTUAN DAN PERUBAHAN KONDISI SOSIAL EKONOMI MASYARAKAT
}

\begin{tabular}{|c|c|}
\hline \multicolumn{2}{|c|}{$\begin{array}{c}\text { Oleh : } \\
\text { Arif Fadilla } \\
\text { Universitas Singaperbangsa Karawang } \\
\text { ariffadila@fe.unsika.ac.id } \\
\text { DOI Artikel : https://doi.org/10.34308/eqien.v6i2.89 }\end{array}$} \\
\hline Article Info & Abstract \\
\hline $\begin{array}{l}\text { Article History: } \\
\text { Received 30 Juli } 2019 \\
\text { Accepted } 14 \text { Agustus } 2019 \\
\text { Available Online 05 September } \\
2019\end{array}$ & $\begin{array}{l}\text { Tapaktuan Port is one of the ports in Aceh Province that is } \\
\text { included in the national port development plan. To support the } \\
\text { plan, this study aims to evaluate the existence of the port based on } \\
\text { consideration of socio-economic aspects. The data collection } \\
\text { method used in this study is a survey method. The results showed } \\
\text { that the presence of Tapaktuan Port lacked a real impact on the } \\
\text { people of South Aceh District. But these results are not the only } \\
\text { consideration in assessing the existence of Tapaktuan Port. } \\
\text { Another consideration is the strategic value of the port as the } \\
\text { lifeline of important commodity trading and disaster mitigation. }\end{array}$ \\
\hline $\begin{array}{l}\text { yword: } \\
\text { aktuan Harbor, } \\
\text { ith Aceh Regency }\end{array}$ & \\
\hline
\end{tabular}

\section{PENDAHULUAN}

Pelabuhan Tapaktuan adalah salah satu pelabuhan yang berada di wilayah Kabupaten Aceh Selatan. Secara geografis, pelabuhan tersebut berada pada teluk yang berbatasan langsung dengan Samudera Hindia pada bagian bagian barat hingga selatan (Wati et al., 2016). Sementara itu, secara astronomis Pelabuhan Tapaktuan terletak pada koordinat $30-15$ ' - 00 " Lintang Utara dan 970 - 11'- 00" Bujur Timur (Dishubkomintel Prov. Aceh, 2011). Pelabuhan ini memiliki status sebagai pelabuhan tidak diusahakan, yakni pelabuhan yang hanya merupakan tempat persinggahan kapal atau perahu tanpa fasilitas bongkar muat, bea cukai dan lainlain (Kemhub, 2018).

Sebagaimana diketahui bahwa keberadaan Pelabuhan Tapaktuan telah berdiri sejak zaman dulu. Pada tahun 1992, pemerintah membangun dermaga modern yang saat ini dinamakan sebagai Dermaga
I. Selanjutnya pada tahun 2007, Badan Rehabilitasi dan Rekonstruksi (BRR) Aceh-Nias membangun Dermaga II setelah musibah gempa dahsyat dan tsunami melanda sebagian wilayah Provinsi Aceh (Nopiana, 2017).

Lebih lanjut menurut Nopiana (2017), Pelabuhan Tapaktuan menjadi salah satu pelabuhan di Provinsi Aceh yang masuk ke dalam rencana pengembangan pelabuhan nasional berdasarkan Rencana Induk Pelabuhan Nasional (RIPN). Pengembangan Pelabuhan Tapaktuan dapat dilihat, dengan ditingkatkannya hierarki pelabuhan tersebut menjadi Pelabuhan Pengumpul sejak tahun 2015. Pelabuhan ini telah menjadi pelabuhan yang fungsi pokoknya melayani kegiatan angkutan laut dalam negeri, dalam jumlah menengah dan sebagai tempat asal tujuan penumpang dan/atau barang serta angkutan penyeberangan dengan jangkauan pelayanan antarprovinsi. 
Merujuk pada rencana pengembangan Pelabuhan Tapaktuan di atas, diperlukan evaluasi terhadap kegiatan pelabuhan tersebut selama ini. Menurut Prijambodo (2014), evaluasi penting untuk dilakukan, sebagai umpan balik (feed back) bagi pengambilan keputusan untuk perencanaan di masa depan. Salah satu aspek yang dipertimbangan dalam melakukan evaluasi adalah aspek sosial ekonomi. Penelitian ini bertujuan untuk memperoleh gambaran tentang dampak keberadaan Pelabuhan Tapaktuan terhadap perubahan sosial ekonomi masyarakat Kabupaten Aceh Selatan. Khususnya dengan melihat perubahan dari sebelum dan sesudah pembangunan fasilitas pelabuhan, termasuk Dermaga II.

\section{KAJIAN PUSTAKA DAN PEGEMBANGAN HIPOTESIS Perubahan Sosial}

Lauer (1993, hlm. 4) mengatakan bahwa "perubahan sosial sebagai suatu variasi atau modifikasi dalam setiap aspek proses sosial, pola sosial, dan bentuk-bentuk sosial, serta setiap modifikasi pola antar hubungan yang mapan dan standar perilaku". Dengan demikian, bahwa perubahan sosial tersebut benar-benar akan memasuki kepada keseluruhan aspek kehidupan sosial. Di mana kehidupan sosial tersebut secara terus menerus akan mengalami suatu perubahan. Tingkat perubahan dari waktu ke waktu pun akan berbeda tergantung pada kondisi masyarakat.

Hal tersebut diperkuat kembali oleh Lauer (1993, hlm.5) bahwa "terdapat kesenjangan waktu, sehingga perubahan yang terjadi pada satu tingkat lebih lambat disbanding yang terjadi pada tingkat lain. Namun tetap saja perubahan di setiap tingkat kehidupan sosial dianggap sebagai perubahan sosial." dapat disimpulkan bahwa seluruh perubahan yang terjadi dalam kehidupan masyarakat disebut sebagai perubahan sosial, yang membedakannya hanya pada tingkat perubahannya saja.

Ogburn (dalam Soekanto, 1983, hlm. 100) mengungkapkan bahwa "perubahan pada satu lembaga sosial, akan mengakibatkan terjadinya perubahan pada lembaga-lembaga sosial lainnya. Dia menyatakan bahwa bagian- bagian dari suatu masyarakat saling berhubungan sebagaimana halnya dengan bagian-bagian dari mesin mobil".

Sehingga dalam aktivitas sosial- ekonomi masyarakat tidak terlepas saling keterkaitan di dalamnya. Karena apabila suatu perekonomian menurun atau membaik, akan mempengaruhi terhadap kondisi sosialnya.

Perubahan sosial merupakan suatu proses secara terus-menerus dalam masyarakat sehingga dari waktu ke waktu masyarakat mengalami perubahan, sekecil apapun itu. Namun perubahan sosial yang terjadi dalam masyarakat satu tidak akan sama dengan masyaraat lainnya. Perubahan dalam masyarakat terdapat berbagai ciri didalamnya, hal tersebut seperti menurut Soekanto (dalam Lumintang, 2015) sebagai berikut:

a. Tidak ada masyarakat yang berhenti perkembangannya karena setiap masyarakat mengalami perubahan yang terjadi secara lambat maupun cepat.

b. Perubahan yang terjadi pada lembaga kemasyarakatan tertentu akan diikuti oleh perubahan pada lembaga-lembaga sosial yang lain.

c. Perubahan yang telah berlangsung sangat cepat, biasanya mengakibatkan disorganisasi karena dalam

masyarakat ada proses penyesuaian diri atau adaptasi. Disorganisasi yang diikuti oleh proses reorganisasi tersebut akan menghasilkan pemantapan kaidah-kaidah dan nilai yang baru.

d. Suatu perubahan tidak dapat dibatasi pada aspek kebendaan atau spiritual saja, karena keduanya mempunyai hubungan timbal balik yang kuat. (hlm. 58)

Berdasarkan ciri-ciri tersebut, terlihat bahwa perubahan sosial tidak akan berhenti perkembangannya apabila telah memasuki kehidupan suatu masyarakat. yang berbeda hanya pada tingkat perkembangan perubahan sosial, yaitu akan cepat maupun lambat. Selain itu, perubahan sosial yang dirasakan masyarakat pada satu aspek, akan menyebabkan perubahan pula pada aspek lainnya. Dan bersifat saling mempengaruhi antara satu sama lainnya.

2.1 Makna Ziarah Makam Wali

Ziarah makam Wali tersebut yang menjadi daya tarik sehingga banyak masyarakat yang melakukan ziarah terletak pada makna yang terkandung di dalamnya. Makna tersebut dapat 
berupa simbol-simbol. Simbol tersebut dapat berupa objek, kejadian atau berupa catatancatatab tertulis yang kemudian dimaknai oleh manusia. Dalam ziarah makam, ritual merupakan suatu hal yang dijalani sebagai aktivitas pada kegiatan ziarah tersebut.

Sutardi (dalam Irmasari, 2013) mengungkapkan bahwa "ritual adalah simbol yang dipakai oleh suatu masyarakat untuk menyampaikan konsep kebersamaan, ritual adalah tempat untuk melebur segala konflik keseharian kepada nilai-nilai spiritual". Ritual dalam ziarah tersebut tidak selalu berupa halhal seperti mantra atau dalam bentuk sesajen, tetapi bisa pula dalam bentuk pembacaan doadoa, tahlil, selawat yang ditujukan untuk mendoakan orang yang dikuburkan.

Hal tersebut diperkuat oleh Yiliyatun (2015, hlm. 346) yang mengungkapkan "sebagian besar para peziarah mengakui bahwa tujuannya berziarah adalah untuk mengenang kembali dan meneladani keshalehan para Wali. Di samping itu juga untuk bertawassul melalui berdzikir, berdoa, dan membaca AlQuran sebagai bentuk refleksi keimanannya kepada Allah SWT".

Ritual yang terdapat dalam ziarah makam tersebut yang akan menjadi tujuan masyarakat ketika melakukan ziarah. Tujuan dalam melakukan ziarah tersebut merupakan refleksi dalam kegiatan ritual, di mana tujuan dari melakukan ritual adalah untuk mendoakan orang yang dikuburkan, meminta barakah, karamah, dan sebagainya.

\section{METODE PENELITIAN}

Metode analisis yang digunakan dalam penelitian ini adalah metode analisis deskriptif. Adapun jenis data yang diperlukan adalah data primer, dengan lingkup populasi adalah masyarakat Kabupaten Aceh Selatan yang memiliki keterkaitan aktivitas dengan Pelabuhan Tapaktuan. Metode pengumpulan data menggunakan metode survei, yang diawali dengan observasi lapangan yang meliputi pengamatan terhadap kondisi fisik serta aktivitas pelabuhan dan sekitarnya. Selanjutnya dilakukan wawancara dan pengisian kuesioner secara terstruktur. Jumlah sampel yang diambil pada penelitian ini adalah 30 responden. Penentuan jumlah responden ditentukan berdasarkan batas minimal dari suatu penelitian sosial yaitu 30 orang (Singarimbun \& Effendi, 2008). Adapun teknik sampling yang digunakan dalam penelitian ini adalah teknik terpilih (purposive sampling), dengan melakukan pemilihan sampel sesuai dengan kriteria yang ditentukan (Nazir, 2014).

\section{HASIL DAN PEMBAHASAN}

Demografi Responden

Jumlah mayoritas responden masyarakat sebagaimana dapat dilihat pada Tabel 1. adalah pria sebesar $83,33 \%$, sedangkan sisanya perempuan sebesar $16,67 \%$. Bagian responden yang paling banyak diwawancarai berusia 30 40 tahun (30\%), disusul responden yang berusia 20-30 tahun (26,68\%). Ditinjau dari hal ini menunjukkan mayoritas responden adalah penduduk berusia produktif (15-64 tahun). Sementara itu dari segi pekerjaan responden, mayoritas responden berprofesi sebagai pegawai swasta dan PNS/TNI/Polri masing-masing sebesar $33,33 \%$. Mayoritas responden bertempat tinggal di Kecamatan Tapaktuan (79,99\%), selain itu mereka bertempat tinggal di sekitar Kecamatan Tapaktuan, seperti Kecamatan Samadua, Pasieraja dan Labuhanhaji.

Perubahan Pekerjaan Utama Masyaraka Secara teoritis, bergesernya pekerjaan penduduk dari sektor ekonomi tradisional (pertanian) ke sektor ekonomi modern (industri dan jasa) menunjukkan indikasi adanya peningkatan produktivitas penduduk, yang selanjutnya berdampak pada meningkatnya pendapatan masyarakat. Berdasarkan hasil survei, mayoritas responden sebanyak 28 orang (93\%) tidak mengalami perubahan pekerjaan sesudah pembangunan Dermaga II. Hal ini dapat disimpulkan bahwa secara umum produktivitas penduduk Aceh Selatan masih relatif rendah, dikarenakan porsi penduduk Kabupaten Aceh Selatan yang bekerja di sektor pertanian relatif tidak berubah. Dengan demikian penambahan fasilitas Pelabuhan Tapaktuan relatif tidak berpengaruh terhadap produktivitas dan pendapatan masyarakat Aceh Selatan. Data lain sesuai 
Tabel 2. menunjukkan sebanyak $100 \%$ responden tidak terlibat langsung dalam pelaksanaan pekerjaan konstruksi pembangunan pelabuhan. Kondisi ini mengindikasikan manfaat saat pembangunan pelabuhan tidak dinikmati oleh masyarakat sekitar. Alasan tersebut dapat disadari, karena pembangunan fasilitas Dermaga II dilakukan oleh BRR Aceh-Nias yang sebagian besar tenaga kerjanya didatangkan dari luar Aceh serta memiliki keterampilan khusus atau tertentu.

Perubahan Harga Lahan

Berdasarkan hasil survei menunjukkan mayoritas responden menyatakan bahwa meningkatnya harga lahan di sekitar Pelabuhan Tapaktuan bukan sebagai akibat dari keberadaan/dibangunnya pelabuhan itu. Peningkatan harga lahan disebabkan perkembangan kota yang cukup pesat dan terbatasnya lahan di wilayah Tapaktuan. Wilayah di sekitar pelabuhan saat ini berkembang menjadi pusat perdagangan dan pemukiman yang padat.

Kenaikan Pendapatan

Berdasarkan hasil survei, mayoritas responden menyatakan bahwa kenaikan pendapatan responden bukan disebabkan keberadaan/dibangunnya pelabuhan Tapaktuan. Peningkatan pendapatan sebagian responden lebih disebabkan aktivitas perdagangan, mengingat di sekitar pelabuhan merupakan wilayah pusat perdagangan di tengah kota. Selain itu, peningkatan pendapatan sebagian responden lainnya disebabkan kenaikan gaji dan tunjangan, karena responden tersebut berprofesi sebagai PNS. Namun demikian, responden yang menikmati kenaikan pendapatan dari keberadaan pelabuhan umumnya berprofesi sebagai buruh bongkar muat pelabuhan atau pedagang yang berjualan di dalam kawasan pelabuhan.

Perubahan Perilaku Masyarakat

Secara teoritis, perubahan perilaku masyarakat antara lain diindikasikan melalui perubahan pola konsumsi masyarakat terhadap barang-barang nonpangan. Jika semakin banyak mengonsumsi barang-barang nonpangan, maka masyarakat dapat dikatakan lebih sejahtera. Hasil survei menunjukkan tidak adanya berpengaruhnya keberadaan/dibangunnya pelabuhan Tapaktuan terhadap perubahan pola konsumsi responden. Sebagian responden yang berprofesi sebagai buruh menyatakan upah mereka sudah tidak layak lagi, sehingga upah buruh yang diperolehnya dihabiskan untuk mengonsumsi kebutuhan sehari-hari, terutama pangan. Sedangkan sebagian responden lain yang berprofesi sebagai wiraswasta beralasan peningkatan kesejahteraan mereka lebih disebabkan berkembangnya usaha mereka yang sejalan dengan berkembangnya aktivitas ekonomi di kota. Sementara itu, responden yang berprofesi sebagai Pegawai Negeri Sipil (PNS) menyatakan peningkatan kesejahteraan mereka disebabkan meningkatnya gaji dan tunjangan. Hal ini dapat berdampak pada relatif mudahnya PNS mengakses kredit dari lembaga keuangan, sehingga lebih mudah untuk memperoleh barang-barang nonpangan, seperti rumah, kendaraan bermotor, barang-barang elektronik dan lain-lain.

\section{SIMPULAN DAN SARAN}

Berdasarkan hasil analisis di atas bahwa secara umum keberadaan Pelabuhan Tapaktuan, dilihat dari aspek sosial ekonomi kurang memberikan dampak yang nyata bagi masyarakat Kabupaten Aceh Selatan. Namun demikian, perlu ditelaah bahwa keberadaan Pelabuhan Tapaktuan dengan segala aktivitas yang dilakukan saat ini masih sangat vital bagi masyarakat, baik masyarakat Kabupaten Aceh Selatan maupun masyarakat kabupaten sekitar. Hal ini dikarenakan Pelabuhan Tapaktuan merupakan jalur perdagangan komoditas strategis (dalam hal ini produk semen), yang memasok kebutuhan untuk wilayah Kabupaten Aceh Selatan dan kabupaten sekitar. Adanya gangguan terhadap aktivitas bongkar muat 
di Pelabuhan Tapaktuan dapat berakibat terjadinya kelangkaan komoditas semen, sehingga harga komoditas tersebut akan melonjak. Hal ini dapat berakibat pada peningkatan laju inflasi daerah, yang pada gilirannya dapat menurunkan kesejahteraan masyarakat secara umum.

Di samping itu, pertimbangan aspek sosial ekonomi di atas tidak menjadi satu-satunya yang dipertimbangkan dalam melakukan kegiatan evaluasi. Selain aspek nilai strategis sebagai urat nadi perdagangan komoditas penting, Keberadaan Pelabuhan Tapaktuan juga dapat ditinjau dalam perspektif mitigasi bencana. Hal ini dikarenakan wilayah Aceh Selatan khususnya dan Wilayah Provinsi Aceh bagian barat pada umumnya merupakan wilayah rawan bencana alam, seperti gempa bumi. Apabila bencana alam terjadi sewaktu-waktu, Pelabuhan Tapaktuan dapat difungsikan dalam penanganan bencana.

Sebagai saran untuk pengembangan Pelabuhan Tapaktuan, diperlukan sinergitas dan koordinasi yang baik antara Pemerintah Kabupaten Aceh Selatan dengan Kementerian Perhubungan. Hal ini bertujuan agar terjadi harmonisasi kebijakan yang dilakukan antara pemerintah pusat dan daerah. Selain itu, sebagai saran untuk penelitian selanjutnya, perlu dilakukan penelitian terhadap persepsi masyarakat dan pemangku kepentingan di Kabupaten Aceh Selatan terhadap keberadaan Pelabuhan Tapaktuan. 


\section{REFERENSI}

Dishubkomintel Prov. Aceh. 2011. Pelabuhan Tapaktuan. Tersedia pada

http://gis.dishubkomintel.acehpro v.go.id/dishubkomintel/?r=fasilit as/_map_detail/169/1000.

Diakses pada tanggal 29 Juli 2019.

Kemhub. 2019. Statistik Perhubungan 2018. Jakarta: PustikomKementerian Perhubungan.

Nazir, M. 2014. Metode Penelitian. Cetakan Kesembilan. Bogor: Penerbit Ghalia Indonesia.

Nopiana, M. 2017. Urgensi peningkatan pemanfaatan Pelabuhan Tapaktuan Kabupaten Aceh Selatan Provinsi Aceh, e-Jurnal Apresiasi Ekonomi, 5(3), 119130.

Prijambodo. 2014. Monitoring dan Evaluasi. Bogor: IPB Press.

Singarimbun, M., Effendi, S. 2008. Metode Penelitian Survei. Jakarta: LP3ES.

Wati, I.P., Purwanto, Prasetyawan, I.B. 2016. Kajian pengaruh bangunan pemecah gelombang tipe sambung pantai terhadap gelombang laut di Pelabuhan Tapaktuan, Aceh Selatan. Jurnal Oseanografi, 5(4), 563-572

Ayu F.S.K, Harafah, L.O.M \& Millia, H. (2016). Kondisi Sosial Ekonomi Masyarakat di Sekitar Pertambangan Nikel di Kecamatan Bahodopi Kabupaten Morowali. Jurnal Ekonomi, 1(1), hlm. 135-145.

Boty, M. (2015). Agama dan Perubahan Sosial (Tinjauan Perspektif Sosiologi Agama). Jurnal Istinbath, 14 (15), hlm. 35-50.

Fathurrohman, M. (2013). Pendidikan Islam dan Perubahan Sosial. Jurnal Tadris, 8 (2), hlm. 250279.
Irmasari, M. 2013. Makna Ritual Ziarah Kubur Angku Keramat Junjung Sirih oleh Masyarakat Nagari Paninggahan. E-Journal UNP.

Lailia, A.N. (2014). Gerakan Masyarakat dalam Pelestarian Lingkungan Hidup (Studi tentang Upaya Menciptakan Kampung Hijau di Kelurahan Gunduh Surabaya), jurnal Politik Muda, 3 (3), hlm. 283-302.

Lauer, R.H. (1993). Perspektif tentang Perubahan Sosial. Jakarta : Rineka Cipta.

Lumintang, J. (2015). Pengaruh Perubahan Sosial Terhadap Kemajuan Pembangunan Masyarakat Di Desa Tara-Tara I. E-Jurnal Acta Diurna, 4 (2).

Munthe, H, M. (2007). Modernisasi dan Perubahan Sosial Masyarakat dalam Pembangunan Peranian: Suatu Tinjauan Sosiologis. Jurnal Harmoni, 2 (1), hlm.1-7.

Nadillah, A.G.A. (2011). Mengaji pada Sunan Gunungjati. Cirebon : Zulfana Cirebon.

Ruyadi, Y. (2010). Model Pendidikan Berbasis Kearifan Budaya Lokal (Penelitian terhadap Masyarakat Adat Kampung Benda Kerep Cirebon Provinsi Jawa Barat untuk Pengembangan Pendidikan Karakter di Sekolah). Proceedings of the 4th International Conference on Teacher Education; Join Conference UPI \& UPSI Bandung, Indonesia

Setiadi, E. M \& Kolip, U. (2011). Pengantar Sosiologi. Jakarta : Kencana Prenada Media Group.

Soekanto, S. (1983). Teori Sosiologi tentang Perubahan Sosial. Jakarta : Ghalia Indonesia.

Sugiyono. (2011). Metode Penelitian Kombinasi (Mix Method). Bandung : Alfabeta. 
Yiliyatun, Y. (2015). Ziarah Wali sebagai Media Layanan Bimbingan Konseling Islam untuk Membangun Keseimbangan Psikis Klien. Jurnal Bimbingan Konseling Islam, 6 (2), hlm. 335354.

Zainuddin. (2008). Perubahan Sosial dalam Perspektif Sosiologi Pendidikan. Jurnal Religia, 7 (3), hlm.750-766.
Zunaidi, M. (2013). Kehidupan Sosial Ekonomi Pedagang di Pasar Tradisional Pasca Relokasi dan Pembangunan Pasar Modern. Jurnal Sosiologi Islam, 3 (1), hlm. 52-64.

Zuriah, N. (2009). Metodologi Penelitian Sosial dan Pendidikan. Jakarta: Bumi Aksara. 